\title{
A Method Based on Elastic Mechanics for Judging Compound Hard Roof and Its Application
}

\author{
Haiyang Wang, ${ }^{1,2}$ Xiang Chen, ${ }^{2}$ Yanmin Zhou, ${ }^{2}$ Binwei Xia, ${ }^{3}$ Jie Wang, ${ }^{2}$ Shulei Zhao, ${ }^{2}$ \\ and Jialiang Liu (iD) ${ }^{1,2}$ \\ ${ }^{1}$ State Key Laboratory Breeding Base of Mountain Bridge and Tunnel Engineering, Chongqing Jiaotong University, \\ Chongqing 400074, China \\ ${ }^{2}$ School of Civil Engineering, Chongqing Jiaotong University, Chongqing 400074, China \\ ${ }^{3}$ State Key Laboratory of Coal Mine Disaster Dynamics and Control, Chongqing University, Chongqing 400044, China
}

Correspondence should be addressed to Jialiang Liu; liujialiang@cqjtu.edu.cn

Received 2 September 2020; Revised 16 September 2020; Accepted 25 September 2020; Published 12 October 2020

Academic Editor: Gang Zhou

Copyright ( 2020 Haiyang Wang et al. This is an open access article distributed under the Creative Commons Attribution License, which permits unrestricted use, distribution, and reproduction in any medium, provided the original work is properly cited.

Compound hard roof overlying coal face is the common disaster factor leading to strong strata behaviors. To solve the longstanding problems of only considering partial factors and large deviation from the actuality when identifying compound hard roof, a mechanical model of compound hard roof based on elastic mechanics is built, from which the stress field distribution equations of compound hard roof are formed and the judging criteria of compound hard roof have been set up. In this essay, 8101 Working Face of Tashan Coal Mine in China is the research object for criteria and analysis of compound hard roof, and the result is testified by similar model tests. The research results have provided a basis for judging and dealing with compound hard roof.

\section{Introduction}

Hard roof overlying stopes has always been a study focus in the field of mining safety [1-5]. In China, about one-third of the coal seam is troubled by compound hard roof overlying, scattering in more than $50 \%$ mining areas [6], such as Datong, Jincheng and Hegang, etc. Mining areas have been beset with problems of hard roof to varying degrees. With such characteristics as large layer thickness, high strength, good integrity, and strong self-stabilization [7-9], it is difficult for hard roofs to fall naturally following with the advance of the working face, thus easily forming a large area of roofs suspending in the goaf, which brings huge potential pressure to the supporting of the working face and roof management [10-12]. Once the suspending roofs collapse suddenly, this will result in a strong shock load, leading to crushing accidents in the working face, causing disasters like abnormal emission [13], impact airflow [14], rock burst $[15,16]$, and coal and gas outburst [17], which poses a severe threat to the safety production in the working face [18].
Study on hard roof now is mostly on monolayer or different layer ones separately, and it focuses on deformation and breaking, catastrophe mechanism, and control technology [19-23]. However, relevant studies and field practice and experience show that there are soft interlayers of lower strength such as mudstones and sandy mudstones between hard roof strata, which can easily cause compound effects of synchronous movement of two-layer and multilayer hard roofs, forming compound hard roofs [24, 25]. The very being of these compound hard roofs makes the strata behaviors in the working face intensify.

For the compound hard roof, compound key strata and its compound effects were first suggested and defined by Qian et al. [26, 27], and the mechanical condition of compound rock strata formation and the related formula are obtained based on material mechanics. Mao et al. [28] studied the compound effects caused by hard roof and calculated the fracture span of compound key strata by the finite element method. Liu et al. [29] conducted an experimental study on seismic response of a large-span and column-free subway station in composite strata and found 
that the upper-soft and lower-hard composite strata had a significant effect on the seismic response of the model structure and soil. Xiong et al. [30] analyzed the structural stability of composite roof based on analytic hierarchy process (AHP) and simulation test, which shows that the decreasing order of influence of these factors on the composite roof structure is as follows: lithology of strata, strata thickness, number of strata, strata location, and interlayer cohesive force.

In the study above, the identification methods of compound hard roof mainly involves theoretical analysis, numerical simulation, and similar model tests. Among them, the traditional theoretical judgment methods are mostly based on material mechanics, which simplifies the models and ignores certain factors (such as roof span and overlying load); therefore, it largely deviates from the actuality. $\mathrm{Nu}$ merical simulation can help analyze different factors, but the parameters set have a huge impact on the results, which can easily contribute to errors in the final judging of compound hard roof. The period length and high cost that come with similar model tests make it impossible to take multiple influencing factors into consideration. However, the stress field distribution equation of the compound hard roof can be got by applying elastic mechanics to study the compound hard roofs, which make it possible to consider comprehensively the factors of compound hard roof and identify them accurately.

To enrich the theories of compound hard roof and improve the identifying accuracy, this essay, based on elastic mechanics, sets up the judgment criteria of compound hard roof. The compound hard roof of 8101 working face in Tashan Coal Mine is judged by applying the judgment criteria, and the judgment result is testified by similar model tests.

\section{A Method Based on Elastic Mechanics to Identify the Compound Hard Roofs}

There are multilayer roofs between the compound hard roofs and the coal seam, which have no influence on the formation and movement of the compound hard roofs. Therefore, the multilayer roofs between the compound hard roofs and the coal seam could be simplified as one layer. Meanwhile, there are multilayer roofs over the $2 \#$ hard rock, which applied a load on the 2\# hard rock equivalently. So the multilayer roofs over the $2 \#$ hard rock could be left out and replaced by a load. Based on the above, the model of compound hard roofs overlying the stope is built. As shown in Figure 1, the model comprises a coal seam and four rock strata (under layer, $1 \#$ hard rock, soft interlayer, and 2\# hard rock) overlying it. 1\# hard rock and 2\# hard rock are hard roof strata of certain thickness, and their strength is significantly higher than that of the soft interlayer. When synchronous movement of $1 \#$ hard rock, soft interlayer, and 2\# hard rock happens, the compound hard roofs form.

\subsection{Identification of Neutral Axis of the Compound Section.} The analysis model of compound hard roofs is built. As shown in Figure 2, with a compound beam of rectangular section composed of three layers of materials, the model has

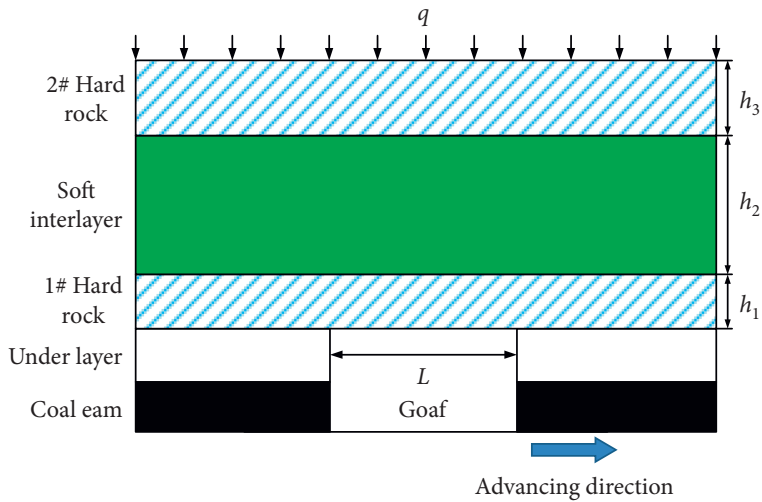

Figure 1: Compound hard roof model.

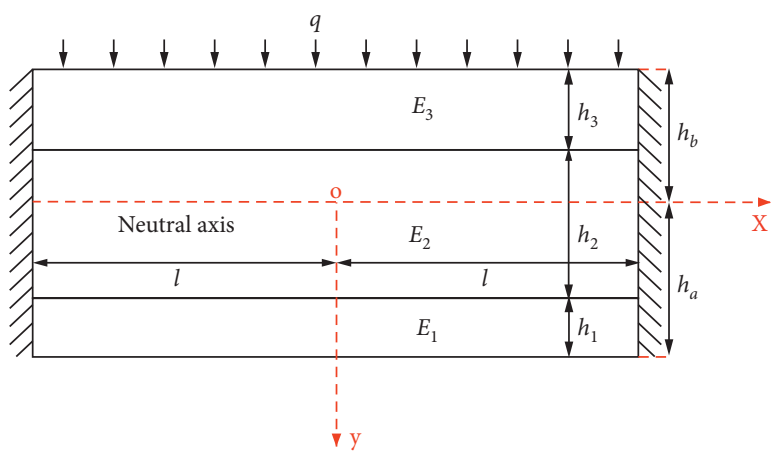

Figure 2: Analysis model of compound hard roof.

1\# hard rock, soft interlayer, and 2\# hard rock from bottom to the top. The rock strata thickness and elasticity modulus are assumed to be $h_{1}, h_{2}, h_{3}$ and $E_{1}, E_{2}, E_{3}$ neutral axis to be in soft interlayer, the distance between the neutral axis and the cross section under 1 \# hard rock to be $h_{a}$, and that above $2 \#$ hard rock to be $h_{b}, h_{1}+h_{2}+h_{3}=h_{a}+h_{b}=h$. The vertical load of the unit area borne by $2 \#$ hard rock is $q$.

According to static relationship, the $h_{a}$ can be got:

$$
h_{a}=\frac{E_{1} h_{1}^{2}+E_{2} h_{2}\left(h_{2}+2 h_{1}\right)+E_{3} h_{3}\left(h_{3}+2 h_{2}+2 h_{1}\right)}{2\left(E_{1} h_{1}+E_{2} h_{2}+E_{3} h_{3}\right)} \text {. }
$$

2.2. Mechanical Model of the Compound Hard Roofs and Analysis. In elastic theory, normal stress $\sigma_{x}, \sigma_{y}$ and shear stress $\tau_{x y}$ in component of stress can be expressed in stress function:

$$
\left\{\begin{array}{c}
\sigma_{x}=\frac{\partial^{2} \varphi}{\partial y^{2}} \\
\sigma_{y}=\frac{\partial^{2} \varphi}{\partial x^{2}} \\
\tau_{x y}=-\frac{\partial^{2} \varphi}{\partial x \partial y}
\end{array}\right.
$$


Among them, caused by direct load, $\sigma_{y}$ does not change with $x$; instead, it is the function of $y$.

Therefore, stress function can be achieved through

$$
\varphi(x, y)=\frac{x^{2}}{2} f(y)+x f_{1}(y)+f_{2}(y) .
$$

Stress equation shall meet consistent equation, and the consistent equation about plane problem is

$$
\frac{\partial^{4} \varphi}{\partial x^{4}}+2 \frac{\partial^{4} \varphi}{\partial x^{2} y^{2}}+\frac{\partial^{4} \varphi}{\partial y^{4}}=0
$$

Substituting formula (3) into consistent equation,

$$
2 \frac{\partial^{2} f(y)}{\partial y^{2}}+\frac{x^{2}}{2} \cdot \frac{\partial^{4} f(y)}{\partial y^{4}}+x \cdot \frac{\partial^{4} f_{1}(y)}{\partial y^{4}}+\frac{\partial^{4} f_{2}(y)}{\partial y^{4}}=0
$$

The coefficient and free terms of the quadratic equation are both zero, which means

$$
\left\{\begin{array}{l}
\frac{\partial^{4} f(y)}{\partial y^{4}}=0, \\
\frac{\partial^{4} f_{1}(y)}{\partial y^{4}}=0, \\
\frac{\partial^{4} f_{2}(y)}{\partial y^{4}}+2 \frac{\partial^{2} f(y)}{\partial y^{2}}=0 .
\end{array}\right.
$$

To meet the above-mentioned requirements, $f(y)$, $f_{1}(y)$ and $f_{2}(y)$ can be assumed:

$$
\left\{\begin{array}{l}
f(y)=A y^{3}+B y^{2}+C y+D, \\
f_{1}(y)=E y^{3}+F y^{2}+G y, \\
f_{2}(y)=-\frac{A}{10} y^{5}-\frac{B}{6} y^{4}+H y^{3}+K y^{2} .
\end{array}\right.
$$

Integrating $f(y), f_{1}(y)$ and $f_{2}(y)$ into stress function $\varphi(x, y)$

$$
\begin{aligned}
\varphi(x, y)= & \frac{x^{2}}{2}\left(A y^{3}+B y^{2}+C y+D\right)+x\left(E y^{3}+F y^{2}+G y\right) \\
& -\frac{A}{10} y^{5}-\frac{B}{6} y^{4}+H y^{3}+K y^{2} .
\end{aligned}
$$

Then, the stress components can be expressed as

$$
\left\{\begin{array}{l}
\sigma_{x}=\frac{x^{2}}{2}(6 A y+2 B)-2 A y^{3}-2 B y^{2}+6 H y+2 K \\
+x(6 E y+2 F), \\
\sigma_{y}=A y^{3}+B y^{2}+C y+D, \\
\tau_{x y}=-x\left(3 A y^{2}+2 B y+C\right)-3 E y^{2}-2 F y-G .
\end{array}\right.
$$

Based on the symmetry of coordinate axis and the continuity condition, stress components can be simplified as

$$
\left\{\begin{array}{l}
\sigma_{x}=3 A x^{2} y-2 A y^{3}+6 H y, \\
\sigma_{y}=A y^{3}+C y+D, \\
\tau_{x y}=-x\left(3 A y^{2}+C\right) .
\end{array}\right.
$$

The stress fields on the down and up sides of the neutral axis are different because above the neutral axis is the pressure zone and below it is the tensile zone. The stress fields in the two parts can be expressed as

Tensile zone: $0 \leq y \leq h_{a}$.

$$
\left\{\begin{array}{l}
\sigma_{x}=3 A_{1} x^{2} y-2 A_{1} y^{3}+6 H_{1} y, \\
\sigma_{y}=A_{1} y^{3}+C_{1} y+D_{1} \\
\tau_{x y}=-x\left(3 A_{1} y^{2}+C_{1}\right) .
\end{array}\right.
$$

Pressure zone: $-h_{b} \leq y \leq 0$.

$$
\left\{\begin{array}{l}
\sigma_{x}=3 A_{2} x^{2} y-2 A_{2} y^{3}+6 H_{2} y, \\
\sigma_{y}=A_{2} y^{3}+C_{2} y+D_{2}, \\
\tau_{x y}=-x\left(3 A_{2} y^{2}+C_{2}\right) .
\end{array}\right.
$$

According to the boundary conditions, equation (12) can be simplified as

$$
\left\{\begin{array}{l}
A_{1} h_{a}^{3}+C_{1} h_{a}+D_{1}=0, \\
3 A_{1} h_{a}^{2}+C_{1}=0 \\
-A_{2} h_{b}^{3}-C_{2} h_{b}+D_{2}=0 \\
3 A_{2} h_{b}^{2}+C_{2}=0
\end{array}\right.
$$

When $y=0, \sigma_{y}$ and $\tau_{x y}$ are constant in value and meet the stress equation of tensile and pressure zones, therefore, $C_{1}=C_{2}, D_{1}=D_{2}$.

The physical equations of the model can be expressed as

$$
\left\{\begin{array}{l}
\varepsilon_{x}=\frac{1}{E}\left(\sigma_{x}-v \sigma_{y}\right), \\
\sigma_{y}=\frac{1}{E}\left(\sigma_{y}-\nu \sigma_{x}\right), \\
\gamma_{x y}=\frac{2(1+\nu)}{E} \tau_{x y} .
\end{array}\right.
$$

In the formula above, $v$ is the Poisson ratio of the rock strata.

The geometric equation can be expressed as

$$
\left\{\begin{array}{l}
\varepsilon_{x}=\frac{\partial u}{\partial x} \\
\varepsilon_{y}=\frac{\partial v}{\partial x} \\
\gamma_{x y}=\frac{\partial u}{\partial y}+\frac{\partial v}{\partial x}
\end{array}\right.
$$


Substituting component stress into the physical and geometry equations,

$$
\left\{\begin{array}{l}
\varepsilon_{x}=\frac{\partial u}{\partial x}=\frac{1}{E}\left[3 A x^{2} y-2 A y^{3}+6 H y-v\left(A y^{3}+C y+D\right)\right] \\
\varepsilon_{y}=\frac{\partial v}{\partial x}=\frac{1}{E}\left[A y^{3}+C y+D-v\left(3 A x^{2} y-2 A y^{3}+6 H y\right)\right] \\
\gamma_{x y}=\frac{\partial u}{\partial y}+\frac{\partial v}{\partial x}=\frac{2(1+v)}{E}\left(-3 A x y^{2}-C x\right) .
\end{array}\right.
$$

Integrating with respect to $\partial u / \partial x$ and $\partial v / \partial x$

$$
\left\{\begin{array}{l}
u=\frac{1}{E}\left[A x^{3} y-2 A x y^{3}+6 H x y-v\left(A x y^{3}+C x y+D x\right)+g_{1}(y)\right] \\
v=\frac{1}{E}\left[\frac{1}{4} A y^{4}+\frac{1}{2} C y^{2}+D y-v\left(\frac{3}{2} A x^{2} y^{2}-\frac{1}{2} A y^{4}+3 H y^{2}\right)+g_{2}(x)\right] .
\end{array}\right.
$$

Substituting $u$ and $v$ into $\gamma_{x y}$,

$$
\frac{1}{E}\left[A x^{3}-6 A(1+v) x y^{2}+6 H x-C v x+g_{1}^{\prime}(y)+g_{2}^{\prime}(x)\right]=\frac{1}{E}\left[-6 A(1+\nu) x y^{2}-2 C(1+v) x\right]
$$

Then, $g_{1}(y)$ and $g_{2}(x)$ can be set as

$$
\left\{\begin{array}{l}
g_{1}(y)=M y+N \\
g_{2}(x)=-\frac{1}{4} A x^{4}-\left(C+3 H+\frac{1}{2} C v\right) x^{2}-M x+P .
\end{array}\right.
$$

When substituting $g_{1}(y)$ and $g_{2}(y)$ into displacement expression, therefore,

$$
\left\{\begin{array}{l}
u=\frac{1}{E}\left[A x^{3} y-2 A x y^{3}+6 H x y-\nu\left(A x y^{3}+C x y+D x\right)+M y+N\right] \\
v=\frac{1}{E}\left[\frac{1}{4} A y^{4}+\frac{1}{2} C y^{2}+D y-v\left(\frac{3}{2} A x^{2} y^{2}-\frac{1}{2} A y^{4}+3 H y^{2}\right)-\frac{1}{4} A x^{4}-\left(C+3 H+\frac{1}{2} C \nu\right) x^{2}-M x+P\right]
\end{array}\right.
$$

Substituting displacement boundary conditions into displacement expression,

$$
\left\{\begin{array}{l}
M=N=0 \\
-\frac{1}{4} A l^{4}-\left(C+3 H+\frac{1}{2} C \nu\right) l^{2}+P=0 \\
A l^{3}+(2 C+6 H+C \nu) l=0
\end{array}\right.
$$

According to Saint-Venant theorem,

$$
\left\{\begin{array}{l}
\frac{3}{2} l^{2}\left(A_{1} h_{a}^{2}-A_{2} h_{b}^{2}\right)-\frac{1}{2}\left(A_{1} h_{a}^{4}-A_{2} h_{b}^{4}\right) \\
+3\left(H_{1} h_{a}^{2}-H_{2} h_{b}^{2}\right)=0 \\
A_{1} h_{a}^{3}-A_{2} h_{b}^{3}+C_{1} h_{a}^{2}+C_{2} h_{b}=q
\end{array}\right.
$$

Based on the analysis above, the following equations can be set up: 


$$
\left\{\begin{array}{l}
A_{1} h_{a}^{3}+B_{1} h_{a}^{2}+C_{1} h_{a}+D_{1}=0, \\
3 A_{1} h_{a}^{2}+2 B_{1} h_{a}+C_{1}=0, \\
-A_{2} h_{b}^{3}+B_{2} h_{b}^{2}-C_{2} h_{b}+D_{2}=0, \\
3 A_{2} h_{b}^{2}+2 B_{2} h_{b}+C_{2}=0, \\
C_{1}=C_{2}, D_{1}=D_{2}, \\
h_{a}+h_{b}=h_{2} \\
-\frac{1}{4} A_{1} l^{4}-\left(C_{1}+3 H_{1}+\frac{1}{2} C_{1} v\right) l^{2}+P_{1}=0 \\
A_{1} l^{3}+\left(2 C_{1}+6 H_{1}+C_{1} v\right) l=0, \\
-\frac{1}{4} A_{2} l^{4}-\left(C_{2}+3 H_{2}+\frac{1}{2} C_{2} v\right) l^{2}+P_{2}=0 \\
A_{2} l^{3}+\left(2 C_{2}+6 H_{2}+C_{2} v\right) l=0, \\
\frac{3}{2} l^{2}\left(A_{1} h_{a}^{2}-A_{2} h_{b}^{2}\right)-\frac{1}{2}\left(A_{1} h_{a}^{4}-A_{2} h_{b}^{4}\right) \\
+3\left(H_{1} h_{a}^{2}-H_{2} h_{b}^{2}\right)=0, \\
A_{1} h_{a}^{3}-A_{2} h_{b}^{3}+C_{1} h_{a}^{2}+C_{2} h_{b}=q .
\end{array}\right.
$$

Working out the equations,

$$
\left\{\begin{array}{l}
A_{1}=-\frac{q}{2 h_{a}^{2} h}, \\
A_{2}=-\frac{q}{2 h_{b}^{2} h}, \\
C_{1}=C_{2}=\frac{3 q}{2 h}, \\
D_{1}=D_{2}=\frac{q h_{a}}{h}, \\
H_{1}=\frac{q l^{2}-3 q h_{a}^{2}(2+v)}{12 h_{a}^{2} h}, \\
H_{2}=\frac{q l^{2}-3 q h_{b}^{2}(2+v)}{12 h_{b}^{2} h} .
\end{array} .\right.
$$

Thus, different components of stress of tensile and pressure zones can be expressed as follows.
Tensile zone: $0 \leq y \leq h_{a}$.

$$
\left\{\begin{array}{l}
\sigma_{x}=-\frac{3 q}{2 h_{a}^{2} h} x^{2} y+\frac{q}{h_{a}^{2} h} y^{3}+\frac{q l^{2}-3 q h_{a}^{2}(2+v)}{2 h_{a}^{2} h} y, \\
\sigma_{y}=-\frac{q}{2 h_{a}^{2} h} y^{3}+\frac{3 q}{2 h} y+\frac{q h_{a}}{h}, \\
\tau_{x y}=\frac{3 q}{2 h_{a}^{2} h} x y^{2}-\frac{3 q}{2 h} x .
\end{array}\right.
$$

Pressure zone: $-h_{b} \leq y \leq 0$.

$$
\left\{\begin{array}{l}
\sigma_{x}=-\frac{3 q}{2 h_{b}^{2} h} x^{2} y+\frac{q}{h_{b}^{2} h} y^{3}+\frac{q l^{2}-3 q h_{b}^{2}(2+v)}{2 h_{b}^{2} h} y, \\
\sigma_{y}=-\frac{q}{2 h_{b}^{2} h} y^{3}+\frac{3 q}{2 h} y+\frac{q h_{a}}{h}, \\
\tau_{x y}=\frac{3 q}{2 h_{b}^{2} h} x y^{2}-\frac{3 q}{2 h} x .
\end{array}\right.
$$

2.3. The Judging Criteria of Compound Hard Roofs. The precondition for compound hard roofs to take shape is that there is no shear moving before synchronous movement. That is to say, shear stress of any point on the cross section shall not surpass the corresponding shear strength limit. From the expression of the shear stress, the maximum value of the shear stress in the compound hard roof is located in natural axis layer. The neutral axis is just assumed in intermediate soft interlayer.

In the tensile zone $0 \leq y \leq h_{a}$, shear stress between 1 \# hard rock and bedding plane of the soft interlayer is expressed as

$$
\tau_{1}=\frac{3 q}{2 h}\left[\frac{\left(h_{a}-h_{1}\right)^{2}}{h_{a}^{2}}-1\right] x .
$$

Equation (27) shows that when $x= \pm l$, the shear stress between $1 \#$ hard rock and soft interlayer bedding plane reaches its maximum value:

$$
\tau_{\operatorname{lmax}}=\frac{3 q}{2 h_{a}^{2} h} l\left(h_{a}-h_{1}\right)^{2}-\frac{3 q}{2 h} l .
$$

Similarly, in the pressure zone $-h_{b} \leq y \leq 0$, the shear stress between $2 \#$ hard rock and soft interlayer bedding plane reaches its maximum value when $x= \pm l$ :

$$
\tau_{2 \max }=\frac{3 q}{2 h_{b}^{2} h} l\left(h_{3}-h_{b}\right)^{2}-\frac{3 q}{2 h} l .
$$

From the expression of shear stress, the shear stress will get smaller with the increase of $y^{2}$. When $y=h_{a},-h_{b}$, the shear stress is 0 , the minimum value. When $y=0$ (neutral axis layer), the shear stress reaches the maximum: 


$$
\tau_{12 \max }=-\frac{3 q}{2 h} l \text { (“- "only stands for the direction of shear stress). }
$$

It shows that, under the impact of shear stress, rock strata interface and neutral axis position are the most vulnerable to shear failure in the compound hard roof.

The shear strengths of the bedding plane between $1 \#$ hard rock, 2\# hard rock, and soft interlayer are $\tau_{C 1}$ and $\tau_{C 2}$, and the shear strength of the soft interlayer is $\tau_{C 12}$. Then, the forming conditions of compound hard roofs are

$$
\left\{\begin{array}{l}
\tau_{1 \max } \leq \tau_{C 1}, \\
\tau_{2 \max } \leq \tau_{C 2}, \\
\tau_{12 \max } \leq \tau_{C 12} .
\end{array}\right.
$$

\section{Identification of Compound Hard Roofs and Analysis}

3.1. Overlying Strata Distribution of 8101 Working Face in Tashan Coal Mine. Located in Datong City of Shanxi Province, Tashan Coal Mine is a huge mine with an annual coal production of over 20 million tons. As shown in Table 1, there are six hard roof rock strata in the overlying strata of Working Face 8101 . Among them, between 1\# hard roof and 2\# hard roof is the mudstone layer, making it possible for compound hard roof to take shape. However, there is no condition for compound hard roof as from $2 \#$ hard roof to $6 \#$ hard roof is the sandstone layer, of which the lithology is slightly different. Therefore, an analysis is conducted of the conditions for compound hard roofs between $1 \#$ hard roof and 2\# hard roof.

3.2. Identification of Shear Strength of Rocks and Bedding Planes. The sandstone and mudstone samples are collected from the roof of 8101 Working Face and then processed into $40 \mathrm{~mm} \times 40 \mathrm{~mm} \times 40 \mathrm{~mm}$ cubic specimen in the lab. After that, a rock shear test under different normal stress conditions is conducted with electrohydraulic servo rock shear testing machine. The result is shown in Table 2.

Figure 3 shows the relationship between the shear strength and the normal stress of the sandstone and mudstone samples. There is an approximate linear relation of direct proportion between the shear strength of the rocks and normal stress. By processing the test data, the cohesive force of the sandstone is $12.065 \mathrm{MPa}$; internal friction angle is $30.77^{\circ}$. The calculation method for sandstone shear strength is $\tau_{1}=0.5954 \sigma_{n}+12.065$. The cohesive force of the mudstone is $2.4803 \mathrm{MPa}$, and the internal friction angle is $46.44^{\circ}$. The calculation method for sandstone shear strength is $\tau_{c}=0.325 \sigma_{n}-0.0183$.

Zhang, a scholar from China University of Mining and Technology, combines lab test and numerical experiment to study the shear characteristics of mudstone and sandstone bedding planes and concludes that the calculation method for shear strength of mudstone and sandstone horizontal bedding planes shall be $\tau_{c}=0.325 \sigma_{n}-0.0183$ [31].
3.3. Identification of Compound Hard Roof. Physical and mechanics parameters of $1 \#$ and $2 \#$ hard roof and soft interlayer are shown in Table 3.

$$
L_{0}=h_{0} \sqrt{\frac{2 R_{t}}{q_{0}}} .
$$

Limit span $L_{0}$ of the tensile fracture that happens to single hard roof rock strata is

In the formula above, $h_{0}$ is rock thickness, $R_{t}$ is the shear strength of the rock strata, and $q_{0}$ is the self-weight load (including self-weight) of all the controlled strata of the hard roofs.

$q_{0}$ can be calculated through the following equation:

$$
q_{0}=\frac{E_{1} h_{1}^{3} \sum_{i=1}^{n} \gamma_{i} h_{i}}{\sum_{i=1}^{n} E_{i} h_{i}^{3}} .
$$

In the equation above, $E_{i}$ is the elasticity modulus of the stratum $i ; h_{i}$ is the thickness of stratum $i ; \gamma_{i}$ is the volume force of stratum $i, \mathrm{MN} / \mathrm{m}^{3} ; n$ is the number of strata controlled by hard roofs.

Calculation shows that the controlled strata overlying 1\# hard roof stretch to the $5.24 \mathrm{~m}$ mudstone, with a controlling range of $17.36 \mathrm{~m}$. The self-weight load (including selfweight) of all the controlled strata of the $1 \#$ hard roof is $0.434 \mathrm{MPa}$. Thus, the limit span of $1 \#$ hard roof is $84.3 \mathrm{~m}$ when it moves alone.

The vertical stress of the $1 \# \sim 2 \#$ hard roofs is about $10 \mathrm{MPa}$, then, the shear strengths of sandstones, mudstones, and bedding planes are 18.02 $\mathrm{MPa}, 13.00 \mathrm{MPa}$, and 3.23 $\mathrm{MPa}$ respectively.

The calculation shows that the neutral axis position $h_{a}=16.91 \mathrm{~m}$ of the three-layer rock stratum is in soft interlayer. At the span of $84.3 \mathrm{~m}$, the shear strength of $1 \#$ hard roof and soft interlayer is $2.000 \mathrm{MPa}$, that of $2 \#$ hard roof and soft interlayer, $2.173 \mathrm{MPa}$. The maximum shear strength of neutral axis bedding is $2.174 \mathrm{MPa}$.

Calculation shows that, at the limit span of 1 \# hard roof, the maximum shearing stress between 1 \# hard roof and soft interlayer and that between $1 \#$ hard roof and soft interlayer are actually less than the shearing strength of bedding plane. Also, the maximum shearing stress of neutral axis layer is less than the shearing strength of mudstone. The synchronous movement will take place as a result of the compound hard roof formed by $1 \#$ hard roof and 2\# hard roof.

\section{Similar Model Test of Deformation and Breaking of Compound Hard Roof}

\subsection{Test Scheme Design}

4.1.1. Test Equipment and Ratio of Similitude. This test was conducted by applying the two-dimension similar simulation test system of electrohydraulic servo. Frame size of the test system is length $\times$ width $\times$ height $=3000 \mathrm{~mm}$ $\times 300 \mathrm{~mm} \times 2000 \mathrm{~mm}$, while the test model size is 
TABLE 1: Rock stratum occurrence of 8101 working face.

\begin{tabular}{|c|c|c|c|}
\hline No. & Lithology & Thickness (m) & \\
\hline 1 & Coarse sandstone & 23.27 & 6\# hard rock \\
\hline 2 & Medium sandstone & 10.42 & $5 \#$ hard rock \\
\hline 3 & Medium sandstone & 8.58 & \\
\hline 4 & Fine sandstone & 6.41 & \\
\hline 5 & Medium sandstone & 10.1 & 4\# hard rock \\
\hline 6 & Coarse sandstone & 9.57 & $3 \#$ hard rock \\
\hline 7 & Coarse sandstone & 2.45 & \\
\hline 8 & Medium sandstone & 16.08 & 2\# hard rock \\
\hline 9 & Mudstone & 5.24 & \\
\hline 10 & Medium sandstone & 12.12 & 1\# hard rock \\
\hline 11 & Sandy mudstone & 9 & \\
\hline 12 & Coal seam & 3.3 & \\
\hline 13 & Sandy mudstone & 1.6 & \\
\hline 14 & Coal seam & 21.02 & \\
\hline 15 & Fine sandstone & 30 & \\
\hline 16 & Medium sandstone & 15 & \\
\hline
\end{tabular}

TABLE 2: Rock shear testing data.

\begin{tabular}{|c|c|c|c|c|c|}
\hline Sandstone specimen & Normal stress $(\mathrm{MPa})$ & Shearing strength $(\mathrm{MPa})$ & Mudstone specimen & Normal stress $(\mathrm{MPa})$ & $\begin{array}{c}\text { Shearing } \\
\text { strength }(\mathrm{MPa})\end{array}$ \\
\hline S-1 & 5 & 16.04 & N-1 & 1 & 3.15 \\
\hline S-2 & 10 & 17.24 & $\mathrm{~N}-2$ & 4 & 7.36 \\
\hline$S-3$ & 15 & 20.54 & N-3 & 7 & 9.11 \\
\hline S-4 & 20 & 23.23 & $\mathrm{~N}-4$ & 10 & 13.97 \\
\hline S-5 & 25 & 27.93 & N-5 & 13 & 15.62 \\
\hline Average & 15 & 21.00 & Average & 7 & 9.84 \\
\hline
\end{tabular}

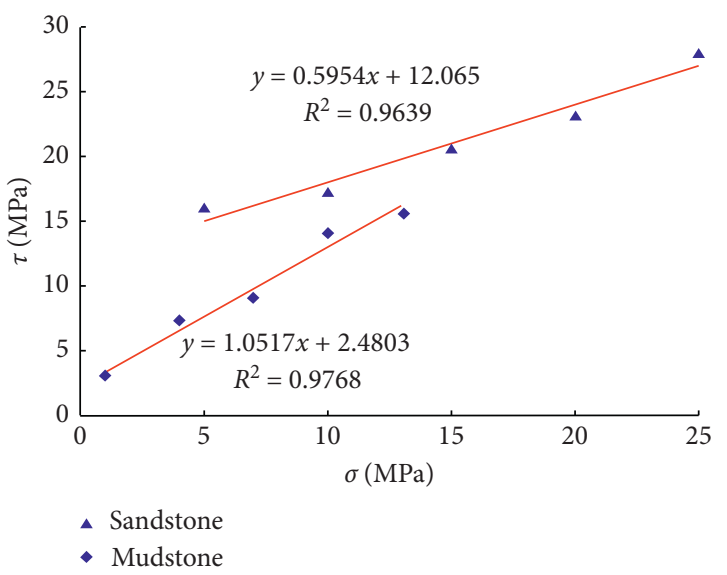

FIgURE 3: Relationship between shear strength and normal stress.

TABLE 3: Mechanics parameters of $1 \#$ and 2\# hard roof and soft interlayer.

\begin{tabular}{lccccc}
\hline Parameter & Thickness $(\mathrm{m})$ & Volume weight $\left(\mathrm{kg} / \mathrm{m}^{3}\right)$ & Compressive strength $(\mathrm{MPa})$ & Tensile strength $(\mathrm{MPa})$ & Elasticity modulus $(\mathrm{GPa})$ \\
\hline 2\# hard roof & 16.08 & 2534 & 59.3 & 10.5 & 27.5 \\
Soft interlayer & 5.24 & 2728 & 39.6 & 6.0 & 12.1 \\
1\# hard roof & 12.12 & 2534 & 59.3 & 10.5 & 27.5 \\
\hline
\end{tabular}


TABLE 4: Similar material proportioning of 8101 working face.

\begin{tabular}{|c|c|c|c|c|c|c|c|c|}
\hline No. & $\begin{array}{l}\text { Model height } \\
(\mathrm{cm})\end{array}$ & $\begin{array}{l}\text { Density } \\
\left(\mathrm{kg} / \mathrm{m}^{3}\right)\end{array}$ & $\begin{array}{l}\text { Ratio NO. (River sand: Line: } \\
\text { gypsum) }\end{array}$ & $\begin{array}{l}\text { River sand } \\
\quad(\mathrm{kg})\end{array}$ & $\begin{array}{l}\text { Line } \\
(\mathrm{kg})\end{array}$ & $\begin{array}{l}\text { Gypsum } \\
(\mathrm{kg})\end{array}$ & $\begin{array}{l}\text { Water } \\
(L)\end{array}$ & $\begin{array}{l}\text { Sodium tetraborate } \\
(\mathrm{kg})\end{array}$ \\
\hline 1 & 16.63 & 1730 & 373 & 168.34 & 39.28 & 16.83 & 22.45 & 0.22 \\
\hline 2 & 4.27 & 1689.33 & 437 & 44.98 & 3.37 & 7.87 & 5.62 & 0.06 \\
\hline 3 & 6.20 & 1689.33 & 437 & 65.36 & 4.90 & 11.44 & 8.17 & 0.08 \\
\hline 4 & 3.17 & 950.67 & 473 & 18.79 & 3.29 & 1.41 & 2.35 & 0.02 \\
\hline 5 & 9.98 & 1689.333 & 637 & 112.72 & 5.64 & 13.15 & 13.15 & 0.13 \\
\hline 6 & 6.98 & 1689.33 & 437 & 73.58 & 5.52 & 12.88 & 9.20 & 0.09 \\
\hline 7 & 15.51 & 1689.333 & 637 & 175.21 & 8.76 & 20.44 & 20.44 & 0.20 \\
\hline 8 & 6.95 & 1689.33 & 437 & 73.23 & 5.49 & 12.81 & 9.15 & 0.09 \\
\hline 9 & 5.72 & 1689.33 & 437 & 60.30 & 4.52 & 10.55 & 7.54 & 0.08 \\
\hline 10 & 4.27 & 1730 & 373 & 43.25 & 10.09 & 4.32 & 5.77 & 0.06 \\
\hline 11 & 6.73 & 1689.33 & 437 & 70.98 & 5.32 & 12.42 & 8.87 & 0.09 \\
\hline 12 & 6.38 & 1689.333 & 637 & 72.06 & 3.60 & 8.41 & 8.41 & 0.08 \\
\hline 13 & 1.63 & 1689.333 & 637 & 18.45 & 0.92 & 2.15 & 2.15 & 0.02 \\
\hline 14 & 10.72 & 1818.67 & 437 & 121.66 & 9.12 & 21.29 & 15.21 & 0.15 \\
\hline 15 & 3.49 & 950.67 & 555 & 21.59 & 2.16 & 2.16 & 2.59 & 0.03 \\
\hline 16 & 8.08 & 1818.67 & 437 & 91.70 & 6.88 & 16.05 & 11.46 & 0.11 \\
\hline 17 & 6.00 & 1730 & 864 & 71.97 & 5.40 & 3.60 & 8.10 & 0.08 \\
\hline 18 & 2.20 & 950.67 & 473 & 13.05 & 2.28 & 0.98 & 1.63 & 0.02 \\
\hline 19 & 1.07 & 1730 & 864 & 12.79 & 0.96 & 0.64 & 1.44 & 0.01 \\
\hline 20 & 14.01 & 950.67 & 473 & 83.13 & 14.55 & 6.23 & 10.39 & 0.10 \\
\hline 21 & 20.00 & 1730 & 373 & 202.41 & 47.23 & 20.24 & 26.99 & 0.27 \\
\hline 22 & 10.00 & 1689.33 & 437 & 105.4144 & 7.90608 & 18.44752 & 13.1768 & 0.131768 \\
\hline
\end{tabular}

length $\times$ width $\times$ height $=2600 \mathrm{~mm} \times 300 \mathrm{~mm} \times 2000 \mathrm{~mm}$. In accordance with similarity criterion, the geometric similarity ratio of the similar model test shall be $1 / 150$ and time similarity ratio $1 / 12.25$, rock stratum volumeweight similarity ratio $1 / 1.5$, and strength similarity ratio $1 / 225$.

According to the time similarity ratio, the $1.96 \mathrm{~h}$ in the similar model test is equivalent to one day in the working face. Every day, 6 to 8 knives of cutting coal take place, and each of them has a depth of $0.8 \mathrm{~m} .7$ knives of cutting coal are set in the similar model test, and the total depth shall be $5.6 \mathrm{~m}$ each day. According to geometric similarity ratio, the excavation length is $4 \mathrm{~cm}$ for every $1.96 \mathrm{~h}$ in the similar model test.

4.1.2. Similar Materials and Proportioning. Similar materials mainly consist of aggregates (river sand, talcum and mica powder, etc.) and cements (parget, lime carbonate and cements, etc.). The river sand is used for aggregates and parget for cements, with lime carbonate added. Mica plate and mica powder are spread between rock stratums for stratification. According to physical and mechanics parameters of coal and rock mass overlying the working face and their similarity ratio, the proportioning of similar material is determined, as shown in Table 4.

The guard boards on the front and back are discharged in three days after the model is completed. Meanwhile, the reflector plates shall be installed while the similar material is not completely hardened. After 7 to 8 days, the mechanical property of the similar material model is relatively stable and the simulation excavation can be conducted. During the excavation, a $40 \mathrm{~cm}$ for coal pillar on both sides of the model is reserved.
4.2. Test Result Analysis. According to the distribution of the rock stratum of 8101 Working Face and proportioning of similar material, a similar material model of 8101 Working Face is built, as shown in Figure 4.

With the advance of the working face, delamination fracture starts to show up on the upper surface of $2 \#$ hard roof and grows to extend in 2\# hard roof with the increase of span. At the same time, synchronous bending subsidence happens to a certain extent to the three layers of rock stratum (1\# and2\# hard roof and soft interlayer). However, apparent delamination fracture does not happen between 1\# and 2\# hard roof and soft interlayer. When the working face progresses to $117.6 \mathrm{~m}$, instant synchronous instability and breaking happen to the three layers, forming a compound hard roof, which corresponds to theoretical analysis. This is the first time the compound hard roof fractures, as shown in Figure 5 .

Figure 5 shows that lots of vertical fractures of cross distribution exist in the fallen bulks of the compound hard roof. Their existence is caused by tensile stress in the process of bending subsidence and rotating deformation of compound hard roof. Horizontal and delamination fractures rarely take place in the fallen bulks (including the rock stratum interior and bedding plane) of the compound hard roof, which explains why few shearing failures happen in the deformation and damage process of compound hard roof and the failure mode mainly takes the form of tensile facture.

As the working face moves on, the brickwork beam structure of Bulk 2 begins to fail, the whole pressing the filling body of the goaf and separates completely from the compound hard roof that has not fallen. The compound hard roof that has not fallen leads to cantilever beam. As shown in Figure 6, when the working face moves to $162.4 \mathrm{~m}$, tensile facture will happen at the upper end of the supporting seat of 


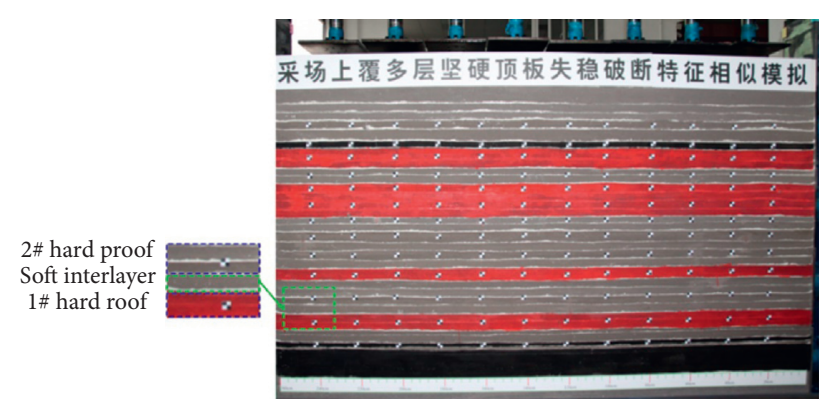

FigURE 4: Similar material model of 8101 working face.

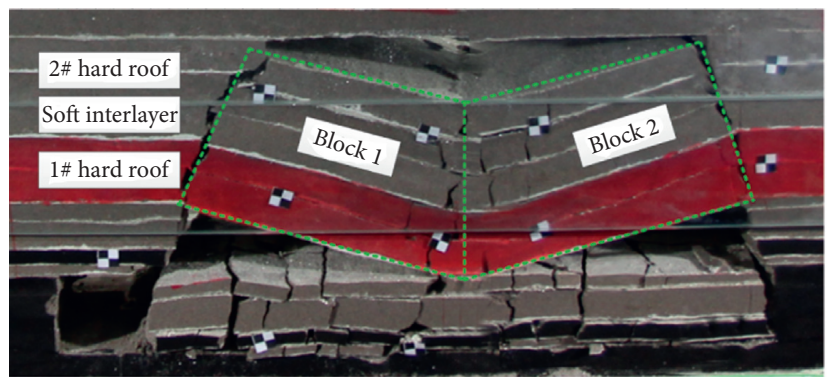

Figure 5: Face advance $117.6 \mathrm{~m}$.

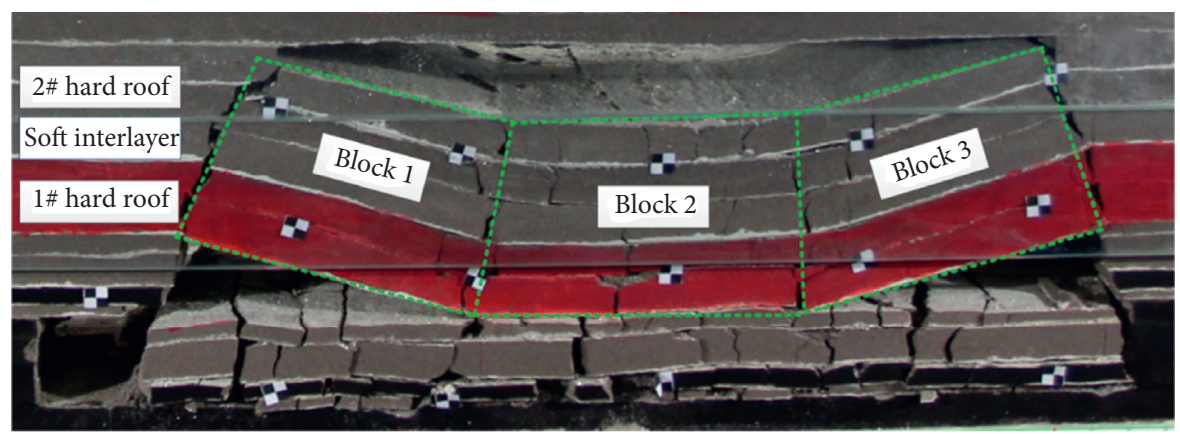

Figure 6: Face advance $162.4 \mathrm{~m}$.

the cantilever beam, causing the whole body to rotate and deform towards the goaf, leading to the structure of "brickwork beam." This is the first periodic failure of the compound hard roof, with a failure span of $44.8 \mathrm{~m}$. In the process of periodic failure of the compound hard roof, no obvious horizontal fracture happens in the rock stratum interior and bedding planes, and the failure mode mainly takes the form of tensile facture.

A similar model test is in line with theoretical analysis, which testifies that the judging criteria for compound hard roof based on elastic mechanics are reliable.

\section{Conclusion}

(1) By applying elastic mechanics theory, a mechanical model of compound hard roof is built, which gets the equations of stress field distribution. According to the distribution features of shearing stress and the maximum shearing stress of bedding planes, the judging criteria for compound hard roof are determined.

(2) Based on the determined judging criteria, the compound hard roof of Working Face 8101 at Tashan is judged. The result shows that the maximum shearing stresses between $1 \#$ and 2\# hard roofs and the soft interlayers, respectively, are less than the shearing strength of bedding planes, and so is the maximum shearing stress of neutral axis layer when compared with the shearing strength of soft interlayers. The synchronous movement will happen as a result of the formation of compound hard roof by $1 \#$ and 2\# hard roofs.

(3) The similar model test verifies the judgment result of the compound hard roof. And the compound hard roof will suffer the synchronous instability and breaking. The break span is pretty large, which will bring huge impact load and easily cause strong strata behaviors. 


\section{Data Availability}

The data used to support the findings of this study are included within the article.

\section{Conflicts of Interest}

The authors declare no conflicts of interest.

\section{Authors' Contributions}

Haiyang Wang and Binwei Xia contributed to developing the mathematical model. Xiang Chen, Yanmin Zhou, Jie Wang, Shulei Zhao, and Jialiang Liu contributed to designing the similar model test scheme and carrying out the test. The paper was written by Haiyang Wang and Xiang Chen. All authors have read and agreed to the published version of the manuscript.

\section{Acknowledgments}

This paper was jointly supported by the National Natural Science Foundation of China (NSFC) (no. 51804058) and the Science and Technology Research Program of Chongqing Municipal Education Commission (grant no. KJQN201800729).

\section{References}

[1] W.-L. Shen, J.-B. Bai, X.-Y. Wang, and Y. Yu, "Response and control technology for entry loaded by mining abutment stress of a thick hard roof," International Journal of Rock Mechanics and Mining Sciences, vol. 90, pp. 26-34, 2016.

[2] M. Tutak and J. Brodny, "The impact of the strength of roof rocks on the extent of the zone with a high risk of spontaneous coal combustion for fully powered longwalls ventilated with the Y-type system-A case study," Applied Sciences, vol. 9, no. 24, p. 5315, 2019.

[3] J. Yang, C. Liu, and B. Yu, "Application of confined blasting in water-filled deep holes to control strong rock pressure in hard rock mines," Energies, vol. 10, no. 11, p. 1874, 2017.

[4] B. Yu, R. Gao, T. Kuang, B. Huo, and X. Meng, "Engineering study on fracturing high-level hard rock strata by ground hydraulic action," Tunnelling and Underground Space Technology, vol. 86, pp. 156-164, 2019.

[5] P. K. Kaiser and M. Cai, "Design of rock support system under rockburst condition," Journal of Rock Mechanics and Geotechnical Engineering, vol. 4, no. 3, pp. 215-227, 2012.

[6] B. Yu, Study on Strong Pressure Behavior Mechanism and Roof Control of Fully Mechanized Top Coal Caving in Extra Thickness Seam in Datong Coal Mine, China University of Mining and Technology, Xuzhou, China, 2014.

[7] G. Wang, X. Liu, H. Xu, M. Wu, R. Wang, and J. Cao, "Study on gas-bearing coal seam destabilization based on the improved Lippmann model and stress wave theory," Journal of Loss Prevention in the Process Industries, vol. 56, pp. 334-341, 2018.

[8] C. Pan, B. Xia, B. Yu, P. Yu, Y. Luo, and Y. Gao, "Determination of the key parameters of high-position hard roofs for vertical-well stratified fracturing to release strong ground pressure behavior in extra-thick coal seam mining," Energy Science \& Engineering, vol. 8, no. 6, pp. 2216-2238, 2020.
[9] Y. Lu, T. Gong, B. Xia, B. Yu, and F. Huang, "Target stratum determination of surface hydraulic fracturing for far-field hard roof control in underground extra-thick coal extraction: a case study," Rock Mechanics and Rock Engineering, vol. 52, no. 8, pp. 2725-2740, 2018.

[10] G.-F. Wang, S.-Y. Gong, Z.-L. Li, L.-M. Dou, W. Cai, and Y. Mao, "Evolution of stress concentration and energy release before rock bursts: two case studies from xingan coal mine, Hegang, China," Rock Mechanics and Rock Engineering, vol. 49, no. 8, pp. 3393-3401, 2015.

[11] B. Yu, "Behaviors of overlying strata in extra-thick coal seams using top-coal caving method," Journal of Rock Mechanics and Geotechnical Engineering, vol. 8, no. 2, pp. 238-247, 2016.

[12] W.-D. Wu, J.-B. Bai, X.-Y. Wang, S. Yan, and S.-X. Wu, "Numerical study of failure mechanisms and control techniques for a gob-side yield pillar in the sijiazhuang coal mine, China," Rock Mechanics and Rock Engineering, vol. 52, no. 4, pp. 1231-1245, 2018.

[13] W. Wang, Y.-P. Cheng, H.-F. Wang, W. Li, and L. Wang, "Coupled disaster-causing mechanisms of strata pressure behavior and abnormal gas emissions in underground coal extraction," Environmental Earth Sciences, vol. 74, no. 9, pp. 6717-6735, 2015.

[14] J. Zhang, B. Li, N. Zhou, and Q. Zhang, "Application of solid backfilling to reduce hard-roof caving and longwall coal face burst potential," International Journal of Rock Mechanics and Mining Sciences, vol. 88, pp. 197-205, 2016.

[15] J. He, L.-M. Dou, Z.-L. Mu, A.-Y. Cao, and S.-Y. Gong, "Numerical simulation study on hard-thick roof inducing rock burst in coal mine," Journal of Central South University, vol. 23, no. 9, pp. 2314-2320, 2016.

[16] T.-B. Zhao, W.-Y. Guo, Y.-L. Tan, Y.-C. Yin, L.-S. Cai, and J.-F. Pan, "Case studies of rock bursts under complicated geological conditions during multi-seam mining at a depth of 800 m," Rock Mechanics and Rock Engineering, vol. 51, no. 5, pp. 1539-1564, 2018.

[17] N. Li, E. Wang, M. Ge, and J. Liu, "The fracture mechanism and acoustic emission analysis of hard roof: a physical modeling study," Arabian Journal of Geosciences, vol. 8, no. 4, pp. 1895-1902, 2015.

[18] Q. Bai, S. Tu, F. Wang, and C. Zhang, "Field and numerical investigations of gateroad system failure induced by hard roofs in a longwall top coal caving face," International Journal of Coal Geology, vol. 173, pp. 176-199, 2017.

[19] A. I. Sofianos and A. P. Kapenis, "Numerical evaluation of the response in bending of an underground hard rock Voussoir beam roof," International Journal of Rock Mechanics and Mining Sciences, vol. 35, no. 8, pp. 1071-1086, 1998.

[20] C. Xu, L. Yuan, Y. P. Cheng, K. Wang, and A. T. Zhou, "Square-form structure failure model of mining-affected hard rock strata, theoretical derivation, application and verification," Environmental Earth Ences, vol. 75, p. 1180, 2016.

[21] H. He, L. Dou, J. Fan, T. Du, and X. Sun, "Deep-hole directional fracturing of thick hard roof for rockburst prevention," Tunnelling and Underground Space Technology, vol. 32, pp. 34-43, 2012.

[22] B. Huang, J. Liu, and Q. Zhang, "The reasonable breaking location of overhanging hard roof for directional hydraulic fracturing to control strong strata behaviors of gob-side entry," International Journal of Rock Mechanics and Mining Sciences, vol. 103, pp. 1-11, 2018.

[23] C.-P. Lu, Y. Liu, H.-Y. Wang, and P.-F. Liu, "Microseismic signals of double-layer hard and thick igneous strata 
separation and fracturing," International Journal of Coal Geology, vol. 161, pp. 28-41, 2016.

[24] Z. J. Hou, "Study on application of combinatorial key stratum theory and parameters determining," Journal of China Coal Society, vol. 26, pp. 611-457, 2001.

[25] J. Q. Jia, H. T. Wang, J. X. Tang, X. H. Li, K. X. Li, and G. Z. Hu, "Determination of key strata and interval of roofing breaking of hard and soft composite roofs," Chinese Journal of Rock Mechanics and Engineering, vol. 25, pp. 974-978, 2006.

[26] M. G. Qian, X. X. Miao, and J. L. Xu, "Theoretical study of key stratum in ground control," Journal of China Coal Society, vol. 21, pp. 225-230, 1996.

[27] X. X. Miao, X. B. Mao, Z. W. Sun, and H. Pu, "Formation conditions of compound key strata in mining overlayer strata and its discriminance," Journal of China University of Mining and Technology, vol. 34, pp. 547-550, 2005.

[28] X. B. Mao, X. X. Miao, and M. G. Qian, "Calculation for fracture span of compound key strata in mining rocks," Rock \& Soil Mechanics, vol. 20, pp. 1-4, 1999.

[29] T. Liu, S. Zheng, X. Tang, and W. Xu, "Experimental study on seismic response of a large-span and column-free subway station in composite strata," Shock and Vibration, vol. 2019, pp. 1-15, 2019.

[30] X. Y. Xiong, J. Dai, and X. Wang, "Comprehensive analysis of stability of coal seam composite roof based on analytic hierarchy process," Advances in Civil Engineering, vol. 21, pp. 225-230, 2019.

[31] Y. Q. Zhang, "Instability and control mechanism of layered compound roof in consideration of shear behavior of bedding plane," Dissertation, China University of Mining and Technology, Xuzhou, China, 2015. 